\title{
Sociodemographic inequalities in eating practices and concerns
}

\author{
Lhais de Paula Barbosa Medina ${ }^{1, *} \oplus$, Marilisa Berti de Azevedo Barros ${ }^{1}$, \\ Regina Mara Fisberg ${ }^{2}$, Daniela de Assumpção ${ }^{3}$ and Antônio de Azevedo Barros Filho ${ }^{3}$ \\ 'Department of Collective Health, School of Medical Science, State University of Campinas, 126 Tessália Vieira de \\ Camargo St, 13083894 Campinas, São Paulo, Brazil: ${ }^{2}$ Department of Nutrition, Public Health School, University of \\ São Paulo, São Paulo, São Paulo, Brazil: ${ }^{3}$ Department of Pediatrics, School of Medical Science, State University of \\ Campinas, Campinas, São Paulo, Brazil
}

Submitted 5 December 2019: Final revision received 29 August 2020: Accepted 14 September 2020: First published online 27 0ctober 2020

\begin{abstract}
Objective: To evaluate associations between selected dietary concerns and eating practices and determine the association of these concerns/practices with demographic and socio-economic characteristics in a population from a large Brazilian city.

Design: Population-based cross-sectional study. We investigated concerns regarding salt intake, the use of highly processed seasoning and the custom of reading the $\mathrm{Na}$ content on food labels. We also analysed concerns regarding the use of pesticides on food products and the practice of consuming organic foods. These variables were analysed according to sex, age group, schooling and income. Multivariate Poisson regression analysis was performed for the estimation of prevalence ratios.

Setting: Campinas, state of São Paulo, Brazil.

Participants: The representative sample consisted of 1710 adults and seniors.

Results: A total $62.3 \%$ of the population were concerned with salt intake, $34.7 \% \mathrm{did}$ not use highly processed seasoning and $10.6 \%$ checked the Na content on food labels; $27.5 \%$ were concerned with pesticides and $26.5 \%$ consumed organic foods. The practices analysed were associated with the respective concerns. Women and seniors had a better profile, except for reading $\mathrm{Na}$ content in both groups and the consumption of organic foods among seniors. The frequency of checking the $\mathrm{Na}$ content and consuming organic foods increased with the level of schooling. The higher income group had a better profile, except for concern with salt intake. Conclusions: Considerable social differences were found regarding the dietary practices, and the practices were associated with concerns. The present findings underscore the need for different dietary counseling strategies targeting specific groups.
\end{abstract}

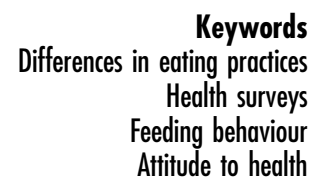

The knowledge that individuals acquire regarding what constitutes a healthy diet exerts an influence on their receptiveness to nutritional guidelines and the recognition of the health benefits of incorporating new eating behaviours or practices. Knowledge acquisition favours the development of attitudes or perceptions related to eating and these attitudes have the potential to be converted into eating practices $^{(1)}$.

Studies report that manifestations of dietary concerns and the good eating practices these concerns tend to generate are associated with better health profiles ${ }^{(2-5)}$. Thus, concerns regarding salt intake ${ }^{(6)}$ and the use of pesticides on food products as well as behaviours such as not using highly processed seasoning ${ }^{(5)}$, reading nutritional information on food labels ${ }^{(2)}$ and consuming organic foods ${ }^{(7)}$ may reflect the interest of individuals in changing their eating practices based on nutritional guidelines.

However, one's living conditions exert a dual influence on the process of knowledge becoming attitude and then practice. On the one hand, one's socio-economic status may or may not ensure the acquisition of knowledge regarding better eating practices ${ }^{(1)}$. On the other hand, even if such knowledge is acquired, one's living conditions can serve either a barrier or facilitator in the process of converting knowledge into perceptions, behaviours and practices $^{(1,8,9)}$. Schooling can determine one's degree of understanding with regard to recommendations related to nutrition and health as well as perceptions regarding 
the need to incorporate these recommendations into one's lifestyle, but income is one of the determinants of the effective possibility of assimilating healthy eating practices ${ }^{(8,10)}$.

The evaluation of eating practices and dietary concerns can contribute to the identification of issues that require greater dissemination, discussion and guidance. Therefore, the aims of the present study were to evaluate associations between selected dietary concerns and selected eating practices and to determine the association among these concerns and practices with sex, age, schooling and income in adults and seniors residing in a large city in southeastern Brazil.

\section{Methods}

The data analysed in the present study were obtained from two population-based cross-sectional studies: the Campinas Health Survey and the 2015/2016 Campinas Nutrition Survey. The surveys collected information from residents of private households in the city of Campinas, state of São Paulo, Brazil. Campinas is located $96 \mathrm{~km}$ from the state capital and had more than 1200000 residents in 2019. It is the fourteenth largest city in the country and the second largest in the state of São Paulo. Its Human Development Index was estimated at 0.805 in 2010, and the urbanisation rate is $98.3 \%{ }^{(11)}$

The sample sizes of the Campinas Health Survey were defined considering the estimate of a 0.50 proportion (corresponding to maximum variability), a $95 \%$ confidence level $(Z=1.96), 4-5 \%$ sampling error and a design effect of 2 , resulting in 1000 adolescents (10-19 years of age), 1400 adults (20-59 years of age) and 1000 seniors (60 years of age or older).

The sample was determined employing a complex, twostage sampling procedure. Seventy census sectors were selected in the first stage, and the second stage consisted of the systematic selection of households in the selected census sectors to obtain independent samples of adolescents, adults and seniors. For the present study, only data from adults and seniors were analysed. Assuming a nonresponse rate of $22 \%$ for adults and $20 \%$ for seniors (based on experience with past surveys), the number of households selected for each of these age groups was, respectively, 1029 and 3157.

The data were collected by trained, supervised interviewers who administered a questionnaire comprising predominantly closed-ended questions with the aid of an electronic device (tablet). The questionnaire was composed of twelve sections addressing morbidities and disabilities, accidents and violence, emotional health, well-being, health behaviours, the use of healthcare services, socio-economic status and household characteristics.

The 2015/2016 Campinas Nutrition Survey collected data on the dietary habits of the same sample. The questionnaire involved a $24 \mathrm{~h}$ recall, questions on the weekly consumption of foods, eating practices and concerns, information on the circumstances of eating, etc. The data were entered into a template developed using the EpiData $3 \cdot 1$ programme.

\section{Study variables}

The dependent variables of this study were concerns and eating practices. The concerns regarded knowledge of the importance of moderate salt intake and the need to avoid the consumption of foods grown with pesticides. The practices analysed were those that indicate the incorporation of eating behaviours, such as the non-use of highly processed seasoning, checking the salt content on food labels and consuming organic foods ${ }^{1}$. These variables were determined based on the following questions:

- $\quad$ Concern with salt intake - 'Are you concerned with the amount of salt you consume in foods?' (yes or no);

- Use highly processed seasoning - 'In your home, are store-bought seasoning products used to prepare meals?' (yes or no);

- $\quad$ Checking the Na content on food labels - 'When buying a food product, do you generally check the information on the label/package?', for which the response options were 'yes', 'sometimes' and 'no'. The respondent was also asked about what type of information was of interest, for which the response options were (a) fat, (b) energies, (c) gluten, (d) fibre, (e) Na, (f) expiration date and $(\mathrm{g})$ other. For this category, individuals who checked the salt content were those who answered 'yes' to the first question and reported ' $\mathrm{Na}$ ' in the second question. All other respondents were in the category 'does not check $\mathrm{Na}$ content on food labels'.

- Concern with the use of pesticides - 'When acquiring/ buying a food product, are you concerned whether pesticides were used in the production of this food' (yes or no);

- Consumption the organic foods with some frequency'Do you consume organic foods or those grown without pesticides?' (yes/sometimes/part of the foods or no).

The independent variables included the following demographic and socio-economic characteristics: sex (male or female), age group (adults: 20-59 years; seniors: $\geq 60$ years), schooling ( $0-4$ and $\geq 5$ years of study) and per capita family income using the Brazilian monthly minimum wage (BMMW) as reference and categorised as $<$ BMMW and $\geq$ BMMW. The BMMW in 2015 was $\mathrm{R} \$ 788$ (Brazilian currency), corresponding to approximately US\$ 152 .

The number of chronic diseases was used to adjust the data in the multivariate analysis and included hypertension (prevalence: $23.0 \%$ ), CVD (angina, acute myocardial infarction, arrythmia or other heart diseases with prevalence of 
11.0\%), cancer (prevalence: $3.2 \%$ ) and other CVD. The number of chronic diseases was categorised as none, one or two, three and four or more.

The prevalence of concerns and eating practices was estimated, and associations were tested using Pearson's $\chi^{2}$ test with the Rao-Scott correction. A $P$-value $<0.05$ was considered indicative of a statistically significant association. The prevalence of each concern and each eating practice was analysed according to the independent variables. The associations were also tested using Pearson's $\chi^{2}$ test. Multivariate Poisson regression analyses with robust variance $^{(12)}$ were performed for the estimation of prevalence ratios (PR) and 95\% CI for the associations between each dependent variable and the independent variables. In the final models, the PR also were obtained by multivariate Poisson regression analyses with robust variance to test the associations between food concerns and eating practices and between these with demographic and socio-economic variables adjusted for sex, age, schooling, income and number of chronic diseases. The non-response weights for households and interviews and the post-stratification weight were considered in the analyses using the survey (svy) model of Stata 14.0 (Stata Corp.).

\section{Results}

Among the households selected for interviews with adults and seniors, the non-response rate was $8.7 \%$ due to refusals and other reasons. Among the individuals identified in the households, the non-response rate was $21 \%$ due to refusals and $1.8 \%$ for other reasons. In the nutrition survey, the non-response rate was $13 \cdot 2 \%$, leading to a final sample of 1710 individuals.

The study population was composed predominantly of women ( $52.9 \%)$ and adults between 20 and 59 years of age (80.9\%). A total of $19.9 \%$ of the overall sample had less than 4 years of schooling and $35.7 \%$ had a family income per capita less than the BMMW. A total of $41.8 \%$ of the sample had two or more chronic diseases (Table 1).

A total of $62.3 \%$ of the population expressed concern with their salt intake; the prevalence of this concern was higher among women and seniors. A percentage of $34.7 \%$ did not use highly processed seasoning in the preparation of meals; the prevalence of this practice was higher among women, seniors and the segment with a higher income. A percentage of $10.6 \%$ reported reading the Na content on food labels; the prevalence of this practice was higher in strata with higher levels of schooling and income. Concerns with the use of pesticides and the consumption of organic foods were reported by 27.5 and $26.5 \%$ of the study population, respectively. The concern with pesticides was higher among women, seniors and the group with a higher income, whereas the consumption of organic foods was greater among women and in strata with higher levels of schooling and income (Table 1).
Table 1 Characteristics of study participants and prevalence (\%) of concerns and eating practices. 2014/15 Campinas Health Survey and 2015/16 Campinas Nutrition Survey ( $n$ 1710)

\begin{tabular}{|c|c|c|}
\hline \multirow[b]{2}{*}{$\underline{\text { Variables }}$} & \multicolumn{2}{|c|}{ Total } \\
\hline & $n$ & $\%$ \\
\hline \multicolumn{3}{|l|}{ Sex } \\
\hline Male & 717 & $47 \cdot 0$ \\
\hline Female & 993 & $52 \cdot 9$ \\
\hline \multicolumn{3}{|l|}{ Age (years) } \\
\hline $20-59$ & 866 & $80 \cdot 9$ \\
\hline 60 or more & 844 & $19 \cdot 0$ \\
\hline \multicolumn{3}{|l|}{ Schooling (years) } \\
\hline $0-4$ & 650 & $19 \cdot 9$ \\
\hline 5 or more & 1059 & $80 \cdot 1$ \\
\hline \multicolumn{3}{|l|}{ Income per capita } \\
\hline$<1 \mathrm{BMMW}^{*}$ & 599 & $35 \cdot 7$ \\
\hline$\geq 1 \mathrm{BMMW}$ & 1110 & $64 \cdot 2$ \\
\hline \multicolumn{3}{|l|}{ Number of chronic diseases } \\
\hline $0-1$ & 771 & 58.9 \\
\hline $2-3$ & 523 & $27 \cdot 9$ \\
\hline 4 or more & 328 & 13.9 \\
\hline \multicolumn{3}{|l|}{ Concerns and eating practices } \\
\hline Concerned with salt intake & 1140 & $62 \cdot 3$ \\
\hline $\begin{array}{l}\text { Does not use highly processed } \\
\text { seasoning }\end{array}$ & 691 & $34 \cdot 7$ \\
\hline Check Na content on food labels & 145 & $10 \cdot 6$ \\
\hline $\begin{array}{l}\text { Concerned with contamination of } \\
\text { foods by pesticides }\end{array}$ & 514 & $27 \cdot 5$ \\
\hline $\begin{array}{l}\text { Consumes organic foods with } \\
\text { some frequency }\end{array}$ & 459 & $26 \cdot 5$ \\
\hline Total & 1710 & 100 \\
\hline
\end{tabular}

*BMMW: Brazilian monthly minimum wage.

Associations were found between the two concerns analysed and the respective practices (Table 2). The prevalence of the non-use of highly processed seasoning was 1.40-fold higher, and the prevalence of checking the $\mathrm{Na}$ content on food labels was $2 \cdot 77$-fold higher among the group that reported being concerned with salt intake compared with those who reported not being concerned. The prevalence of eating organic foods was 3.35-fold higher in the group who reported being concerned with the use of pesticides on food products compared with those who reported not being concerned.

The prevalence of all practices and concerns investigated, with the exception of checking the Na content on food labels, was higher among women. The largest difference between sexes was found regarding the concern with the contamination of food by pesticides, which was $43 \%$ higher among the women (Table 3). Higher frequencies of concerns with salt intake and the use of pesticides and the practice of not using store-bought spice blends were found among the seniors with greater magnitude of differences observed for the non-use of highly processed seasoning ( $P R=1.44)$ (Table 3$)$. The greatest differences between schooling strata regarded the checking the $\mathrm{Na}$ content on food labels ( $\mathrm{PR}=4 \cdot 06)$. Moreover, the consumption of organic foods increased with the increase in schooling (Table 3). The frequency of all practices and concerns analysed, except the concern with salt intake, 
Table 2 Prevalence (\%) of eating practices among adults and seniors according to concerns. 2014/15 Campinas Health Survey and $2015 / 16$ Campinas Nutrition Survey $(n 1710)$

\begin{tabular}{|c|c|c|c|c|c|c|c|c|c|}
\hline \multirow[b]{4}{*}{ Variables } & \multicolumn{4}{|c|}{ Concerned with salt intake } & \multirow[b]{4}{*}{$P$-value* } & \multirow{2}{*}{\multicolumn{4}{|c|}{ Adjusted prevalence ratio $†$}} \\
\hline & \multirow{2}{*}{\multicolumn{2}{|c|}{$\begin{array}{c}\text { No } \\
n 572 \\
(1)\end{array}$}} & \multirow{2}{*}{\multicolumn{2}{|c|}{$\begin{array}{c}\begin{array}{c}\text { Yes } \\
n 1138\end{array} \\
(2)\end{array}$}} & & & & & \\
\hline & & & & & & \multicolumn{2}{|c|}{$(2 / 1) \dagger$} & \multicolumn{2}{|c|}{$(2 / 1) \ddagger$} \\
\hline & $\%$ & $95 \% \mathrm{Cl}$ & $\%$ & $95 \% \mathrm{Cl}$ & & $\%$ & $95 \% \mathrm{Cl}$ & $\%$ & $95 \% \mathrm{Cl}$ \\
\hline $\begin{array}{l}\text { Does not use highly } \\
\text { processed seasoning }\end{array}$ & $25 \cdot 4$ & $20 \cdot 2,31 \cdot 4$ & $40 \cdot 4$ & $35.5,45.5$ & 0.0001 & 1.50 & $1.18,1.89$ & 1.40 & $1 \cdot 12,1 \cdot 75$ \\
\hline \multirow{3}{*}{$\begin{array}{l}\text { Checks Na content on } \\
\text { food labels }\end{array}$} & $4 \cdot 6$ & $2 \cdot 4,8 \cdot 5$ & $14 \cdot 3$ & $11 \cdot 2,17 \cdot 9$ & 0.0001 & $3 \cdot 12$ & $1 \cdot 71,5 \cdot 71$ & $2 \cdot 77$ & $1.54,4.99$ \\
\hline & \multicolumn{4}{|c|}{$\begin{array}{l}\text { Concerned with contamination } \\
\text { of foods by pesticides }\end{array}$} & & & & & \\
\hline & $\begin{array}{c}\text { No } \\
n 1197\end{array}$ & & $\begin{array}{c}\text { Yes } \\
n 513\end{array}$ & & & & & & \\
\hline $\begin{array}{l}\text { Consumes organic foods with } \\
\text { some frequency }\end{array}$ & $15 \cdot 7$ & $12 \cdot 6,19 \cdot 4$ & 54.9 & $47 \cdot 1,62 \cdot 5$ & $<0.0001$ & 3.46 & $2 \cdot 74,4 \cdot 37$ & $3 \cdot 35$ & $2 \cdot 67,4 \cdot 19$ \\
\hline
\end{tabular}

*Adjusted for sex and age.

$\dagger P$-value obtained by Pearson's $\chi^{2}$ test with the Rao-Scott correction.

$\ddagger$ Adjusted for sex, age, schooling, income and number of chronic diseases.

Table 3 Prevalence ratio of eating practices and concerns among adults and seniors according to demographic and socio-economic indicators, adjusted by sex, age, schooling, income and number of chronic diseases. 2014/15 Campinas Health Survey and 2015/16 Campinas Nutrition Survey $(n$ 1710)

\begin{tabular}{|c|c|c|c|c|c|c|c|c|c|c|}
\hline \multirow[b]{2}{*}{ Variables } & \multicolumn{2}{|c|}{$\begin{array}{l}\text { Concerned with } \\
\text { salt intake }\end{array}$} & \multicolumn{2}{|c|}{$\begin{array}{l}\text { Does not use } \\
\text { highly processed } \\
\text { seasoning }\end{array}$} & \multicolumn{2}{|c|}{$\begin{array}{c}\text { Check } \mathrm{Na} \\
\text { content on food } \\
\text { labels }\end{array}$} & \multicolumn{2}{|c|}{$\begin{array}{l}\text { Concerned with } \\
\text { contamination of } \\
\text { foods by } \\
\text { pesticides }\end{array}$} & \multicolumn{2}{|c|}{$\begin{array}{l}\text { Consumes } \\
\text { organic foods } \\
\text { with some } \\
\text { frequency }\end{array}$} \\
\hline & PR & $95 \% \mathrm{Cl}$ & PR & $95 \% \mathrm{Cl}$ & PR & $95 \% \mathrm{Cl}$ & PR & $95 \% \mathrm{Cl}$ & PR & $95 \% \mathrm{Cl}$ \\
\hline Sex (female) & 1.22 & $1.09,1.37$ & 1.16 & $1.01,1.33$ & 1.33 & $0.87,2.04$ & 1.43 & $1.23,1.68$ & 1.25 & $1.02,1.53$ \\
\hline Age (seniors) & $1 \cdot 18$ & $1.04,1.33$ & 1.44 & $1 \cdot 22,1 \cdot 70$ & 0.96 & $0.67,1.37$ & 1.33 & $1.09,1.63$ & $1 \cdot 15$ & $0.95,1.44$ \\
\hline Schooling ( 5 years or more) & 1.04 & $0.93,1.16$ & 1.04 & $0.86,1.25$ & 4.06 & $2.17,7.59$ & $1 \cdot 14$ & $0.89,1.47$ & 1.46 & $1.17,1.83$ \\
\hline Income per capita $\left(\geq\right.$ BMMW $\left.^{\star}\right)$ & 1.09 & $0.96,1.24$ & 1.36 & $1.06,1.76$ & 2.95 & $1 \cdot 66,5 \cdot 25$ & 1.57 & $1 \cdot 17,2 \cdot 12$ & 1.59 & $1 \cdot 20,2 \cdot 10$ \\
\hline
\end{tabular}

*BMMW: Brazilian monthly minimum wage.

was higher in groups with a higher income. The major differences between income strata regarded checking the $\mathrm{Na}$ content on food labels $(\mathrm{PR}=2.95)$ and concerns with the use of pesticides ( $\mathrm{PR}=1.57$ ) (see online supplementary material, Supplemental Table 1).

\section{Discussion}

In the present study, high concern with salt intake was observed to be associated with the non-use of highly processed seasoning and the frequent reading of the $\mathrm{Na}$ content on the food label. Approximately one-quarter of the participants reported being concerned about pesticide use and most of them reported consuming organic foods with some frequency. The differences observed according to gender, age, education and income varied in their magnitude with the best profiles observed among women, seniors and in the groups with higher education and income. The biggest differences were observed for reading of the Na content on the food label in the high education and high-income groups, for the concern about pesticides among women and for non-use of processed seasonings among seniors.

A large proportion of the population studied (62.3\%) reported being concerned with their salt intake. A study conducted in five countries of the Americas found that, on average, $60.7 \%$ of the population reported wanting to reduce the amount of salt that they consume, and the prevalence ranged from $46.3 \%$ in Ecuador to $70.8 \%$ in Argentina $^{(13)}$. Despite the high prevalence of the concern with salt found in the present investigation, another study conducted with data from 2015/16 Campinas Nutrition Survey detected mean $\mathrm{Na}$ intake as high as $3.3 \mathrm{~g} / \mathrm{d}^{(14)}$. The fact that the concern with salt consumption does not 
necessarily converge into a lower intake of this mineral may result from several factors. Those factors include the lack of knowledge on the risk of high salt consumption, on the amount of salt present in different kinds of food, like ultra-processed foods, and personal preferences developed during life ${ }^{(15-17)}$. The WHO recommends that the daily $\mathrm{Na}$ intake for adults not surpass $2 \mathrm{~g}$, which is equivalent to $5 \mathrm{~g}$ of table salt ${ }^{(18)}$, but in Brazil, the mean $\mathrm{Na}$ intake is $3.7 \mathrm{~g} / \mathrm{d}^{(19)}$.

A total of $34.7 \%$ of the participants studied reported not using highly processed seasoning. Highly processed seasoning, such as store-bought bouillon cubes, has a high content of $\mathrm{Na}$, fat and synthetic additives ${ }^{(15)}$ and is generally used to enhance the flavour of foods. A study conducted in a large Brazilian city identified greater $\mathrm{Na}$ intake among individuals who frequently used ready-made seasoning ${ }^{(5)}$. However, no studies were found comparing the $\mathrm{Na}$ content in highly processed seasoning and home seasoning. The literature indicates that the practice of seasoning foods at home enables individuals greater control over the amount of salt added, favouring a reduction in dietary $\mathrm{Na}$ intake, which is preferable to the use of highly processed seasoning ${ }^{(20)}$. However, some processed seasoning products may have low-Na versions, such as lowNa soy sauce, and consumers could also decide to use only a fraction of the content in the package.

The low prevalence of checking the Na content on food labels $(10.6 \%)$ is similar to that reported in a study conducted with individuals surveyed at primary care units in the city of Niterói, Brazil $(11.9 \%)^{(16)}$. The literature indicates a lower frequency of checking the Na content compared with sugar and fat contents ${ }^{(21)}$ and has revealed that a large proportion of individuals (56-89\%) are not capable of interpreting information on salt through the publication of the $\mathrm{Na}$ content on the labels of products ${ }^{(22)}$

Approximately one-fourth of the participants reported being concerned with the use of pesticides on food products. The issue of pesticide use in Brazil has particularities. Since 2008, the country has been the largest consumer of pesticides in the world ${ }^{(23,24)}$, and Brazilian lawmakers have experienced strong pressure to facilitate and expand the use of pesticides despite the harmful effects of these products $^{(25)}$. However, the perception of this problem was low in this studied population, which may at least partly be due to the predominant agricultural production in Brazil based on large properties of land, monocultures and the intensive use of pesticides ${ }^{(26)}$.

The prevalence of the occasional consumption of organic foods was $26.5 \%$. Brazilian legislation has a wider definition compared with the legislation of other countries, considering the organic foods produced from different agroecological crops that in addition predict a production without the use of pesticides, considers principles of sustainability and social justice ${ }^{(27)}$. Internationally, definitions for organic foods are usually restricted to foods produced without the use of industrial chemicals, such as fertilizers and pesticides ${ }^{(26)}$. A study conducted with the Brazilian population detected that $15 \%$ of the respondents reported having consumed some organic product in the previous month, ranging from $10 \%$ in the southeastern region of the country to $34 \%$ in the southern region ${ }^{(28)}$.

The results of the present study revealed that the concern with salt intake was associated with the practice of not consuming highly processed seasoning and was even more strongly associated with the practice of checking the $\mathrm{Na}$ content on food labels. Likewise, a study conducted with adults in the United States in 2012 found that the prevalence of reading food labels and the choice of foods with a low salt content was higher among individuals who recognised that excessive salt intake was harmful to one's health and those who had received advice from a healthcare provider to reduce the amount of salt in their diet ${ }^{(6)}$.

A strong association was found between the concern with the use of pesticides and the practice of eating organic foods. The literature indicates a tendency for consumers to choose organic foods not only because they do not contain pesticides, what is good for their health, but also due to concerns regarding environmental impact ${ }^{(29)}$. Thus, a recent behaviour is detected of consumers choosing 'clean' foods ${ }^{(30)}$.

The prevalence of concern with salt intake was higher among women and seniors. A study conducted by Claro et al. also found that women and seniors reported being more concerned with the harm caused by excessive salt intake ${ }^{(13)}$. Women are often in charge of family eating practices ${ }^{(31)}$ and are generally more engaged, aware and better informed regarding health-related issues ${ }^{(32)}$. Seniors generally have a greater number of chronic diseases and, consequently, they use more healthcare services, where they may receive counseling on health and eating practices ${ }^{(33)}$.

The prevalence on non-used highly processed seasoning was higher among women, seniors and the higher income group. The Dietary Guide for the Brazilian Population places considerable emphasis on cooking skills, which involve everything from the selection of ingredients to the presentation of the meal, as a way of promoting healthy eating. Such skills have historically been the domain of women, which may explain the lower frequency of the use of highly processed seasoning by women in the present study. Moreover, cooking skills are transmitted from generation to generation, which is a process that has been losing momentum in Brazil and other countries in the world, leading to a situation in which older people have this accumulated knowledge and younger people have increasingly less autonomy in the preparation of meals ${ }^{(15)}$. Groups with a higher income may consume less highly processed seasoning by eating out more often, as indicated in a study conducted with the population of adults in Brazil ${ }^{(34)}$, or by eating a larger number of fast foods, which do not require any preparation ${ }^{(35)}$.

About the differences found in the practice of checking the Na content on food labels, as in the present investigation, a 
Brazilian study found a greater frequency of this practice in the group with a higher level of schooling ${ }^{(16)}$. Other studies have also consistently identified a higher frequency of label reading among individuals with higher levels of schooling and income ${ }^{(2,36)}$. The difficulty of consumers in interpreting information on salt through the $\mathrm{Na}$ content presented on the labels ${ }^{(22)}$ may be one of the determinants of the low prevalence of checking this content in the studied population as well as the greater prevalence of this practice in the segment with more schooling. The income differences found in this practice may be the consequence of the greater consumption of industrialised foods in segments with a higher income in the adult population in Brazil ${ }^{(37)}$, as all such products have labels.

The prevalence of concern with the use of pesticides on food products was higher among women, seniors and the higher income group. The differences in sex and age detected in the present investigation may be due to the fact that women and seniors tend to recognise health risks more than men and younger individuals ${ }^{(17,38)}$. However, the prevalence of the consumption of organic foods was higher among women as well as the groups with higher schooling and income. Women also consumed more organic foods than men in a study conducted in a large Brazilian city, and this difference is at least partially due to the fact that women tend to consume healthier foods than men and adhere more to health guidelines ${ }^{(15,38)}$. The seniors, despite presenting a better profile for all practices, do not consume organic foods more frequently than younger. In general, the seniors tend to choose their food based on behaviours and preferences established in the past ${ }^{(17)}$, and organic foods is a concept more recently valued.

As in other countries, the price of organic foods in Brazil is quite high mainly due to the high costs of monitoring and certification processes ${ }^{(26)}$. Although there are Brazilian initiatives regarding participative certification (obtained from groups of rural producers rather than certificating firms) ${ }^{(26)}$ and for the shortening of organic food trade and distribution chains through the implementation of farmer's markets, community-supported agriculture and consumer groups, these items are economically unviable for a large proportion of the population ${ }^{(26)}$. Among the participants in a survey conducted by Brazilian Council of Organic and Sustainable Production - Organis, 62\% reported that price was the main barrier to the consumption of organic foods ${ }^{(28)}$. A Brazilian study conducted by Andrade et al. also found price to be the main impediment to the consumption of organic foods ${ }^{(39)}$. Another factor is the high concentration of wealth in $\mathrm{Brazil}^{(40)}$, which impedes certain segments of the population from having access to these foods. A study conducted by Claro \& Monteiro revealed that expenditure on food accounts for a higher relative percentage of household expenses among poor Brazilian families compared with those with a higher income ${ }^{(10)}$. This at least partly explains the income difference found regarding the consumption of organic foods in the present investigation.

The present study has limitations that should be considered when interpreting the findings. Data obtained through interviews are subject to information bias, as respondents tend to give answers that they consider to be more acceptable. The questions addressing eating practices and concerns did not compose specific, validated instruments, but were similar to those used in previous studies investigating the frequency of such practices ${ }^{(13,39,41,42)}$. The strength of this study regards the use of a representative sample of the population of a highly urbanised city with more than a million residents and the analysis of eating practices and dietary concerns rarely studied.

A strong association between dietary concerns and practices was detected, and considerable demographic and socio-economic differences were found regarding these concerns and practices. Better profiles were generally found among women, seniors and groups with higher schooling and income.

Our results reveal the need for greater dissemination of the knowledge on the health risks of high $\mathrm{Na}$ intake and on the correspondence between salt and $\mathrm{Na}$. Also the need of government strategies to reduce the $\mathrm{Na}$ content in processed foods and seasonings and to encourage families to reduce their salt ingestion.

The findings about concern with pesticides indicate the need for more discussion and the dissemination of knowledge on this issue to pressure in the country for a reduction in the use of these chemicals. About the organic foods, to increase consumption, strategies are needed to popularise this practice and subsidise production, which would result in a reduction in prices that could broaden consumption by segments that currently have no access to these products.

\section{Conclusions}

The results also suggested that further studies need to be conducted in order to better understand the paths that lead subjects to convert concerns into eating practices.

\section{Acknowledgements}

Acknowledgements: None. Financial support: This research was supported by the Foundation for Research Support of the State of São Paulo (FAPESP) for funding the research and the Brazilian Ministry of Health, through Health's Secretary of Campinas. Foundation for Research Support of the State of São Paulo and Brazilian Ministry of Health had no role in the design, analysis or writing of this article. M.L.P.B. is supported by FAPESP and B.M.B.A. by a Research Productivity Grant from CNPq. Conflict of interest: There are no conflicts of interest. Authorship: As the first author, I attest that all the authors have made substantial contribution to this study. I (L.P.B.M.) conceptualised the 
study and did the statistical analyses, the literature review and the writing; M.B.A.B. contributed in the conceptualisation of the study and in the literature review and writing; R.M.F., D.A. and A.A.B.F. contributed in the review of literature and the writing. All the authors revised the content of this paper and approved the final version. Ethics of buman subject participation: This study was conducted according to the guidelines laid down in the Declaration of Helsinki, and it was approved by the Ethics Committee of the School of Medical Science. Written informed consent was obtained from all subjects.

\section{Supplementary material}

For supplementary material accompanying this paper visit https://doi.org/10.1017/S1368980020003638

\section{References}

1. Macías YF \& Glasauer P (2014) Guidelines For Assessing Nutrition-Related Knowledge, Attitudes and Practice. Rome, Italy: FAO.

2. Campos S, Doxey J \& Hammond D (2011) Nutrition labels on pre-packaged foods: a systematic review. Public Health Nutr 14, 1496-1506.

3. Jordan Lin CT, Lee JY \& Yen ST (2004) Do dietary intakes affect search for nutrient information on food labels? Soc Sci Med 59, 1955-1967.

4. Kesse-Guyot E, Péneau S, Méjean C et al. (2013) Profiles of organic food consumers in a large sample of french adults: results from the Nutrient-Santé Cohort Study. PLoS One 8, e76998.1-13.

5. Oliveira LS, CoelhoJS, Siqueira JH et al. (2019) Relate urinary sodium/potassium and consumption of industrialized condiments and ultra-processed foods. Nutr Hosp 36, 125-132.

6. Patel D, Cogswell ME, John K et al. (2017) Knowledge, attitudes, and behaviors related to sodium intake and reduction among adult consumers in the United States. Am J Health Promot 31, 9-18.

7. Álvarez Castaño LS, Cadavid Castro MA, Quintero Vergara SD et al. (2019) Organic food consumption: is it possible to develop public policy? A case study of Medellín. Nutr Hosp 36, 640-646.

8. Darmon N \& Drewnowski A (2008) Does social class predict diet quality? Am J Clin Nutr 87, 1107-1117.

9. Mozaffarian D (2016) Dietary and policy priorities for cardiovascular disease, diabetes, and obesity - a comprehensive review. Circulation 12, 187-225.

10. Claro RM \& Monteiro CA (2010) Family income, food prices and home purchase of fruits and vegetables in Brazil. Rev Saúde Pública 44, 1014-1020.

11. Brazilian Institute of Geography and Statistics IBGE Cities: Panorama of Campinas (2020) https://cidades.ibge.gov.br/ brasil/sp/campinas/panorama (accessed July 2020).

12. Barros AJ \& Hirakata VN (2003) Alternatives for logistic regression in cross-sectional studies: an empirical comparison of models that directly estimate the prevalence ratio. BMC Med Res Methodol 3, 21.

13. Claro R, Linders H, Ricardo C et al. (2012) Consumer attitudes, knowledge, and behavior related to salt consumption in sentinel countries of the Americas. Rev Panam Salud Publica 32, 265-273.
14. Ruiz AMP, Lima MG, Medina LPB et al. (2020). Can meals outside homes impact sodium intake? Curr Dev Nutr $\mathbf{4}$, nzaa091.

15. Brazil. Healthy Ministry (2014) Food Guide for the Brazilian Population Food Guide for the Brazilian Population. http:// bvsms.saude.gov.br/bvs/publicacoes/guia_alimentar_ populacao_brasileira_2ed.pdf (accessed July 2020).

16. Lindemann IL, Silva MT, César JG et al. (2016) Reading food labels among users of primary care and associated factors. Cad Saúde Colet Rio de Janeiro 24, 478-486.

17. Kuwae CA, Carvalho MCVS, Prado SD et al. (2015) Conceptions of healthy nourishment among elderly persons attending the University of the Third Age at UERJ: nutrition, body and daily living guidelines. Revista Brasileira de Geriatria e Gerontologia 18, 621-630.

18. World Health Organization (2012) Sodium intake for adults and children. Guidel Potassium Intake Adults Child. http:// www.who.int/nutrition/publications/guidelines/sodium_ intake/en/ (accessed July 2020).

19. Mill JG, Malta DC, Machado IE et al. (2019) Estimation of salt consumption by the Brazilian population: result of the 2013 National Health Survey. Rev Bras Epidemiol 22, Suppl. 2, E190009, 1-14.

20. Nakadate M, Ishihara J, Iwasaki M et al. (2018) Effect of monitoring salt concentration of home-prepared dishes and using low-sodium seasonings on sodium intake reduction. Eur J Clin Nutr 72, 1413-1420.

21. Webster JL, Li N, Dunford EK et al. (2010) Consumer awareness and self-reported behaviours related to salt consumption in Australia. Asia Pac J Clin Nutr 19, 550-554.

22. Bhana N, Utter J \& Eyles H (2018) Knowledge, attitudes and behaviours related to dietary salt intake in high-income countries: a systematic review. Curr Nutr Rep 7, 183-197.

23. Jardim ANO \& Caldas ED (2012) Brazilian monitoring programs for pesticide residues in food - results from 2001-2010. Food Control 25, 607-616.

24. Carneiro FF (2015) Dossier ABRASCO: a warning about the impacts of pesticides on health/Organization of Fernando Ferreira Carneiro, Lia Giraldo da Silva Augusto, Raquel Maria Rigotto, Karen Friedrich e André Campos Búrigo. Rio de Janeiro: EPSJV; São Paulo: Expressão Popular. http://www.abrasco.org.br/dossieagrotoxicos/wp-content/ uploads/2013/10/DossieAbrasco_2015_web.pdf (accessed July 2020).

25. Moraes R (2019) Pesticides in Brazil: usage patterns, regulation policy and prevention of regulatory capture -2506 . Discussion text/Institute of Applied Economic Research Brasillia: Rio de Janeiro. https://www.ipea.gov.br/portal/ images/stories/PDFs/TDs/td_2506.pdf (accessed July 2020).

26. Lima SK, Galiza M, Valadares A et al. (2020) Production and consumption of organic products in the world and in Brazil 2538. Discussion text/Institute of Applied Economic Research - Brasília: Rio de Janeiro: Ipea, 1990- ISSN 14154765. https://www.ipea.gov.br/portal/images/stories/PDFs/ TDs/td_2538.pdf (accessed July 2020).

27. Brazil. Decree no6.323, of December, 2007 (2007) Regulates Law 10.831, of December 23, 2003, which provides for organic agriculture, and provides other measures. Brasília. http://www.planalto.gov.br/ccivil_03/leis/2003/110.831.htm\#: $\sim$ :text=LEI\%20No\%2010.831\%2C\%20DE\%2023\%20DE\%20DE ZEMBRO\%20DE\%202003.\&text=Regulamento.,Art (accessed July 2020).

28. Brazilian Council for Organic and Sustainable Production (2017) Consumption of Organic Products in Brazil. Curitiba: Organis. https://organis.org.br/pesquisa-consumode-produtos-organicos-no-brasil-2017/ (accessed July 2020).

29. van de Vijver LP \& van Vliet ME (2012) Health effects of an organic diet - consumer experiences in the Netherlands. J Sci Food Agric 92, 2923-2927. 
30. Reeves WR, McGuire MK, Stokes M et al. (2019) Assessing the safety of pesticides in food: how current regulations protect human health. Adv Nutr 10, 80-88.

31. Fonseca AB (2011) Dietary modernity and food consumption: socio-anthropological contributions to research in nutrition. Cien Saúde Colet 16, 3853-3862.

32. Ek S (2015) Gender differences in health information behaviour: a finnish population-based survey. Health Promot Int 30, 736-745.

33. Szwarcwald CL, Souza Júnior PRB, Damacena GN et al. (2015) Recommendations and practice of healthy behaviors among patients with diagnosis and diabetes in Brazil: National Health Survey (PNS), 2013. Rev Bras Epidemiol 18, Suppl. 2, 132-145.

34. Bezerra IN, Moreira TMV, Cavalcante JB et al. (2017) Food consumed outside the home in Brazil according to places of purchase. Rev Saude Publica 51, 15.

35. Medina LPB, Barros MBA, Sousa NFS et al. (2019) Social inequalities in the food consumption profile of the Brazilian population: National Health Survey, 2013. Rev Bras Epidemiol 22, Suppl. 2, E190011, 1-15.

36. Kang HT, Shim JY, Lee YJ et al. (2013) Reading nutrition labels is associated with a lower risk of metabolic syndrome in Korean adults: the 2007-2008 Korean NHANES. Nutr Metab Cardiovasc Dis 23, 876-882.

37. Simões BS, Barreto SM, Molina MCB et al. (2018) Consumption of ultra-processed foods and socioeconomic position: a cross-sectional analysis of the Brazilian Longitudinal Study of Adult Health. Cad Saúde Pública 34, e00019717.

38. Grzymisławska M, Puch EA, Zawada A et al. (2020) Do nutritional behaviors depend on biological sex and cultural gender? Adv Clin Exp Med 29, 165-172.

39. Andrade LMS \& Bertoldi MC (2012) Attitudes and motivations regarding the consumption of organic food in Belo Horizonte - MG. Braz J Food Technol 5, 31-40.

40. Oxfam Brasil (2017) Inequalities in Brazil: the divide that unites us. https://www.oxfam.org.br/um-retrato-das-desigual dades-brasileiras/a-distancia-que-nos-une/?_ga $=2.8023410$. 1705052804.1593875337-1337883588.1593875337 (accessed July 2020).

41. Nakasato M (2004) Salt and hypertension. Rev Bras Hipertens 11, 95-97.

42. Soares MMA, Zuchi AP, Lopes CVA et al. (2019) Perception of health advisors on pesticides: the role of social participation in a sick society. Saúde Soc 28, 337-349. 